\title{
Oxygen therapy for infants with chronic lung disease
}

\author{
S Kotecha, J Allen
}

Supplemental oxygen is a safe and effective treatment for infants with established chronic lung disease who are not at risk of further progression of retinopathy of prematurity (ROP). Oxygen saturations of $<92 \%$ should be avoided and a target range of at least $94-96 \%$ aimed for. The saturation target range for very preterm infants at risk of developing ROP is more controversial, but the therapeutic index is probably considerably narrower.

See end of article for authors' affiliations

\section{Correspondence to:} Dr Kotecha, Department of Child Health, University of Leicester, Leicester LE2 7LX, UK; sk43@le.ac.uk nfants with chronic lung disease of infancy (CLD) and hypoxaemia requiring supplemental oxygen are likely to be a problem as long as preterm deliveries continue to occur. Antenatal and postnatal corticosteroids have decreased the prevalence of respiratory distress syndrome, and the use of lower inspired oxygen tensions and reduced positive inspiratory pressures during mechanical ventilation has contributed to a lower prevalence of CLD. In infants surviving increasingly premature delivery, antenatal and postnatal infection and patent ductus arteriosus both contribute to the development of CLD. ${ }^{1}$ Discussed below is the rationale and aims of oxygen therapy in infants with CLD. The following article by Professor Abman focuses on cardiovascular aspects in children with CLD.

Although the potentially damaging effects of oxygen toxicity must be recognised and avoided, there are clear reasons why the administration of supplemental oxygen to hypoxaemic infants with CLD is beneficial. Alveolar hypoxia is a well described cause of pulmonary artery hypertension resulting from hypoxic pulmonary vasoconstriction. Supplemental oxygen reverses hypoxic pulmonary vasoconstriction, improving oxygen saturation, decreasing pulmonary vascular resistance, and improving right ventricular performance and peripheral oxygen delivery. ${ }^{23}$ Abman reported cardiac catheterisation findings of significant decreases in pulmonary artery pressure, from 48 to $25 \mathrm{~mm} \mathrm{Hg}$, in infants with CLD given $80 \%$ oxygen, and found that most of the benefit occurred at much lower oxygen concentrations which could be administered by nasal cannula at home. ${ }^{4}$ Some infants who do not respond fully to oxygen may have further decreases in pulmonary artery hypertension with the administration of hydralazine, although this appears to be contraindicated in infants with large systemic to pulmonary collateral vessels. ${ }^{5}$

\section{RATIONALE AND PHYSIOLOGICAL EFFECTS OF SUPPLEMENTAL OXYGEN}

Arch Dis Child Fetal Neonatal Ed 2002;87:F1 1-F14

Infants with CLD who are oxygen dependent can have a difficult first few years, often not growing well and requiring frequent readmission to hospital for respiratory exacerbations. ${ }^{6}$ Right ventricular hypertrophy resolves, but only gradually. ${ }^{36}$ Groothuis and Rosenberg ${ }^{7}$ found, however, that supplementation with oxygen at home enabled oxygen dependent infants to grow as well as healthy full term infants. Inappropriately early discontinuation of oxygen caused a significant deceleration in weight gain, which again improved when oxygen supplementation was restarted.

The effects of chronic hypoxaemia on growth of the central nervous system and its effects on developmental status have been studied. It is difficult to separate the long term consequences of adverse neurological events associated with premature delivery from those of chronic postnatal hypoxaemia. Lifschitz et $\mathrm{al}^{8}$ described a two year follow up of infants with CLD with birth weights of less than $1500 \mathrm{~g}$ : 20\% had hearing impairment or were registered blind, $30 \%$ had cerebral palsy, and $46 \%$ had abnormal developmental scores. Whereas the requirement for oxygen at hospital discharge did not predict developmental score, a history of intraventricular haemorrhage and pulmonary air leak and the length of hospital stay did. Doyle et al ${ }^{9}$ performed an eight year follow up of infants with birth weights less than $1000 \mathrm{~g}$. Contrary to the authors' expectations, children who had received less oxygen and ventilation had poorer growth and more severe cerebral palsy. Although this may have been surprising in that children who required more oxygen may have been expected to have more severe disease and therefore more adverse outcomes, it may indicate that programmes aimed at aggressively normalising oxygen saturations may help to avert adverse neurological outcomes.

\section{IDEAL OXYGEN SATURATION TARGETS:} RISKS AND BENEFITS OF OXYGEN

Within days of normal full term birth, arterial oxygen partial pressure approximates that seen in the normal adult. It is therefore logical to aim for saturations of $95-99 \%$ in the full term (or equivalent postconceptional age) and older infant. However, in premature infants with immature retinae, high inspired oxygen concentrations were clearly linked to the development of retinopathy of prematurity (ROP) in the 1940s and 1950s. ${ }^{10}$ (Oxidant injury may also play a role in the pathogenesis of CLD.) Most of the controversy about

Abbreviations: $C L D$, chronic lung disease; $R O P$, retinopathy of prematurity 
the saturation targets of oxygen therapy clearly surrounds the preterm infant who has not yet reached term postconceptional age. In reaction to the threat of ROP associated with unrestricted supplemental oxygen, many took the opposite approach, severely restricting supplemental oxygen. It has been estimated that, as a result, 16 children died or survived with severe disability for every child whose sight was saved. ${ }^{11}$ More recent approaches with cautious oxygen restriction found reduced incidence and severity of ROP without unduly increased death rates. ${ }^{12}$ Although until recently, oxygen saturations of $96-99 \%$ were considered unsafe for the retinal vessels of the premature infant, and values of $90-95 \%$ were targeted instead, new evidence on the safety of higher saturation targets has recently appeared. In the United States, a multicentre trial of 649 oxygen dependent premature infants with moderately severe ROP ("STOP-ROP" study) determined the effect on progression from prethreshold to threshold ROP of two different oxygen saturation targets: 89-94\% and 96-99\%. "Threshold ROP" is defined as ROP severe enough to warrant laser therapy or cryotherapy. This study found no adverse effect with the higher saturation targets, and in some cases risk of progression was even decreased ( $48 \%$ to $41 \%$ ). Using similar number needed to treat analysis as above, it has been estimated that about 13 infants with prethreshold ROP need to be treated with supplemental oxygen to prevent one child needing retinal surgery. Of some concern, however, was the finding of a marginally higher incidence of pulmonary complications in the infants treated with the higher saturation targets.

In contrast, Tin et al ${ }^{14}$ retrospectively studied the records of 295 infants born before 28 weeks gestation and found that saturation targets as low as $70-90 \%$ were associated with significantly less threshold disease (4\% incidence) than saturation targets of $88-98 \%$ ( $18 \%$ incidence). The STOP-ROP and Tin studies are difficult to compare because the STOP-ROP trial prospectively studied only infants with prethreshold ROP, in whom the risk for progression to threshold is understandably higher, whereas the retrospective study of Tin et al examined all preterm births. Both studies seem to agree that the risk of progression to threshold ROP is much reduced after 30-32 weeks postconceptional age. ${ }^{14}{ }^{15}$ Tin et al have readily admitted that their paper generates a hypothesis that lower oxygen saturations may be acceptable. There is obvious concern about accepting lower oxygen saturations in view of potential cardiac, neurological, and growth consequences. The multicentre Australian "BOOST" study may go some way to addressing this issue. The trial, we believe, is studying the effects on growth, health, and development of infants with CLD (irrespective of their ROP status) randomised to the same two target oxygen saturation ranges used in the STOP-ROP trial.

One understudied risk factor is wide swings of oxygen saturation, irrespective of the absolute percentage saturation. There is some speculation that the vascular damage related to hypoxia or hyperoxia may be more a consequence of sudden decreases and increases in oxygen level, which are associated with episodic oxidant damage, rather than hypoxia or hyperoxia per se. Evidence for this exists for ROP but not for the lung. ${ }^{16}$ If this were true, it would argue for closer continuous saturation monitoring.

No matter what oxygen saturations are targeted for infants with CLD at home, it must be recognised that significant oxyhaemoglobin desaturation can occur during periods of feeding or sleep, and appropriate adjustments in supplemental oxygen levels should be made during these periods. Clinically unsuspected hypoxaemia often occurs in infants with CLD, and to a lesser extent with prematurity alone than in control full term infants. ${ }^{17}$ Desaturation seems more severe during feeding than during wakefulness, active, and quiet sleep. Singer et $a l^{18}$ described similar problems in infants with CLD but found that hypoxaemia was more severe after feeding than during. It has been speculated that such desaturation puts these infants at higher risk of sudden unexplained death. ${ }^{17}$ Sleep state related changes in control of breathing could also affect sleeping oxygen saturation levels. Sekar and Duke ${ }^{19}$ described more central apnoea and desaturation in sleeping infants with CLD than in preterm controls; oxygen saturation, central apnoea, and periodic breathing all improved with supplemental oxygen therapy, which may have improved central respiratory stability. Such sleep related decreases in oxygen saturation are worsened by certain positions-for example, sleeping in a "containing posture" or hammock, which has been proposed to have advantageous neurodevelopmental effects in preterm infants. ${ }^{20}$ Abnormal sleep architecture in infants with CLD helps to maintain oxygen saturation by increasing arousals. ${ }^{21}$ This sleep fragmentation and decreased REM sleep can be improved with supplemental oxygen. A targeted saturation of at least $93 \%$ optimises sleep architecture in these infants. ${ }^{22}$ In summary, oxygen saturations of $<92 \%$ should be avoided and a target range of $94-96 \%$ aimed for. Such a range will provide a buffer zone against desaturations during feeding and sleep.

\section{EQUIPMENT FOR MONITORING OXYGEN SATURATION}

Non-invasive monitoring of transcutaneous $\mathrm{Po}_{2}\left(\mathrm{PTCCO}_{2}\right)$ and percentage oxyhaemoglobin saturation has revolutionised our ability to accurately track oxygenation status. Pulse oximetry can accurately track changes in arterial blood gas saturation in the $80-100 \%$ range measured over a wide range of heart rate, blood pressure, packed cell volume, $\mathrm{PCO}_{2}$, and $\mathrm{pH}$ values in infants with CLD, and seems to be more accurate than $\mathrm{PTCCO}_{2}{ }^{23}{ }^{24}$ This is also true in very low birthweight infants. ${ }^{25}$ Other advantages of pulse oximeters over $\mathrm{PTCCO}_{2}$ monitors are that the instruments do not require calibration or cause skin burns. Accuracy of pulse oximetry does diminish in the lower ranges of oxygen saturation. ${ }^{26}$ More sophisticated use of pulse oximetry has enabled it to be used as more than simply a monitoring device. Bhutani $e t a l^{27}$ described a system whereby feedback from a pulse oximeter provided online adjustment of $\mathrm{FIO}_{2}$ according to an adaptive programme. Such adaptive $\mathrm{FIO}_{2}$ control achieved a steady oxygen saturation of $94-96 \%$ for $81 \%$ of the time, compared with $54 \%$ of the time using a standard neonatal intensive care protocol. Such adaptive programmes may be particularly useful in not only achieving oxygen saturation target ranges, but in also preventing widely varying swings in oxygen saturation.

\section{DISCHARGE PLANNING}

Oxygen therapy does not require a hospital environment, and major benefits accrue from discharging stable infants with CLD while they are still receiving supplemental oxygen. The major benefit is promotion of normal development and parent-infant bonding, which is best achieved in the environment of the home. Considerable financial benefits are achieved for the health care system (not necessarily for the family), and the risk of nosocomial infection is eliminated, although counselling against exposure to viruses from ill relatives and friends at home must be given. Sending premature infants home while they are receiving oxygen therapy requires careful planning to ensure success, taking into account a number of patient, family, financial, home, and community factors. This is best done in the context of an organised programme of discharge planning and parent education. ${ }^{28}$ These have recently been discussed (ATS BPD statement; in review). The infant needs to be first and foremost medically stable, showing good growth and without frequent events leading to desaturation and $\mathrm{CO}_{2}$ retention. ${ }^{30}$ If chronic $\mathrm{CO}_{2}$ retention is present, it is preferably controlled at less than 50 torr or so, although higher levels may be acceptable if stable; some form of intermittent non-invasive or invasive, or 

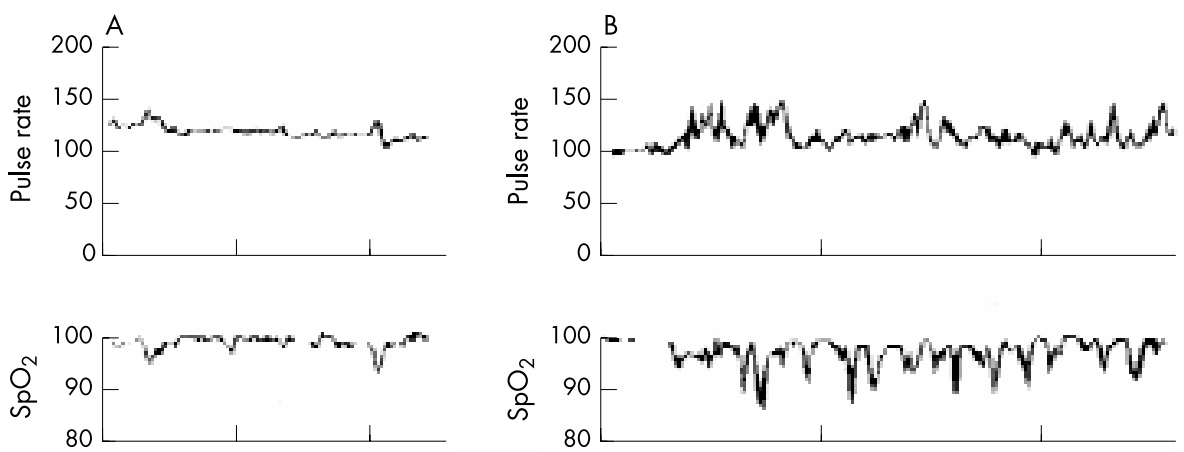

Figure 1 Continuous monitoring of oxygen saturation of infants. (A) Trace from an infant recently weaned off oxygen. Note that the average oxygen saturation in air is consistently $>95 \%$. (B) Trace from an oxygen dependent infant with chronic lung disease (CLD). Note the numerous desaturations falling consistently below $90 \%$. Although there was no clinical evidence, oesophageal $\mathrm{pH}$ monitoring showed appreciable gastro-oesophageal reflux. After treatment for reflux, the oxygen desaturations improved, but oxygen dependency continued for several more months because of CLD. The $x$ axis shows time with 20 minute intervals.

continuous invasive ventilatory assistance aimed at resting the respiratory muscles may be occasionally required to achieve these goals.

The duration of home oxygen therapy has varied widely. Beca et al ${ }^{30}$ reported a mean duration of 71 days (range 7-339). The mean age of discontinuation of home oxygen therapy has been reported to be 13.4 months, but again varies widely. Baraldi et $a^{32}$ reported that, in a prospective home oxygen therapy programme, infants with CLD were discharged at a mean age of 3.7 months, mean duration of oxygen therapy was 97 days (range 15-320), and the mean age of discontinuation of oxygen was 6.9 months (range 3-14.7). Infants improved at home; right ventricular hypertrophy resolved in most, and there was no further progression of ROP, but weight gain remained sluggish at the third centile.

\section{EQUIPMENT FOR DELIVERING OXYGEN}

A number of methods are available for delivering oxygen. ${ }^{33}$ Oxygen concentrators are best suited for infants with CLD who require low flows of between 0.06 and 0.8 litres $/ \mathrm{min} .{ }^{34}$ They work by filtering air through a series of filters to remove particulate matter (including bacteria) and nitrogen with the resultant oxygen stored in a reservoir before use. Usually two outlets are sufficient: one in the main living room area and another in the child's bedroom. Oxygen cylinders (PD size) are essential for mobility, and the newer cylinders made of aluminium are much lighter than the traditional steel ones. Liquid oxygen, which is stored at $-183^{\circ} \mathrm{C}$, is more suitable when the oxygen requirements are high. As most infants require less than 1 litre of oxygen per minute, this is only occasionally used in infants with CLD. The general practitioner currently prescribes these items, and the local oxygen company will provide both training and a 24 hour back up service for the parents or guardians. Low flow oxygen is delivered in most cases through a nasal cannula. In addition to back up provided for the equipment, access to 24 hour medical care is also essential especially at times of intercurrent viral illness.

\section{CARE IN THE COMMUNITY}

Many centres in the United Kingdom have developed the use of specialist respiratory nurses for monitoring children at home on oxygen, although a number of other people are essential for the service. These include dieticians, health visitors, general practitioners, hospital and community paediatricians, social workers as well as other professionals such as physiotherapists and speech therapists. Initially, after discharge, the infant is seen frequently especially as parental anxiety is likely to be high. At each visit, the child's progress is monitored with particular attention to the respiratory, cardiovascular, and neurological systems, and to the growth of the child. Any parental anxiety is addressed, and the children are also seen within the hospital setting on a regular basis. "Spot" checks of oxygen saturations are insufficient to guide oxygen therapy, and prolonged monitoring of oxygen saturation by pulse oximetry while the child is awake, feeding, and asleep is likely to provide a more accurate picture of the child's respiratory status. Modern software will rapidly analyse the data stored in pulse oximeters, and, according to preset parameters, identify episodes of hypoxaemia as well as the average oxygen saturation (fig 1). Arterial or indeed capillary blood gases are rarely performed in the stable situation, and transcutaneous monitors are rarely used. Management of the cardiovascular system is discussed in more detail in the following article.

\section{WEANING FROM HOME OXYGEN}

No uniform standards are used in weaning infants from home oxygen. Most commonly, prolonged pulse oximetry (fig l) is used to determine when it is appropriate to wean infants from supplemental oxygen, using target saturation values similar to those used during oxygen supplementation. Weaning is also likely to be influenced by other factors, including associated medical problems (for example, pulmonary hypertension), somatic growth, and sometimes the weather. It should also be remembered that saturation measurement when the infant is awake may not reflect sleeping saturations. Moyer-Mileur et $a l^{35}$ compared saturations during short term (20-30 minute) awake studies with prolonged sleeping studies in infants with CLD, and found no correlation. Furthermore, they compared infants whose supplemental oxygen was discontinued on the basis of normal short term studies, but who had saturations of 88-91\% during prolonged sleep studies, with infants who had saturations of greater than $92 \%$ during prolonged sleep studies. The infants with lower saturations had a significant decrease in weight gain (from 17.3 to $3.7 \mathrm{~g} / \mathrm{kg} /$ day), z scores for weight gain, and weight for height compared with the infants with higher saturations.

Longer awake studies using higher saturations as targets may allow more accurate prediction of which infants will tolerate discontinuation of oxygen at home. Vermeulen et $a^{36}$ showed that infants who could be weaned from oxygen had awake median saturations of $97 \%$ during one hour awake studies, spent only $14 \%$ of time with saturation $\geqslant 95 \%$ and $2 \%$ of time $\geqslant 92 \%$. Two hour room air challenges were used by Simoes $\mathrm{et} \mathrm{l}^{37}$ to determine suitability for weaning from room air. They found that in most infants, the lowest saturation levels were reached by 40 minutes after the discontinuation of oxygen and that all infants receiving oxygen flow rates 
$\geqslant 20 \mathrm{ml} / \mathrm{kg}$ were able to maintain room air saturations $\leqslant 92 \%$. Such infants were able to maintain weight and height centiles six months after oxygen had been discontinued.

Whether oxygen is weaned early or late after discharge home is not as important as weaning while maintaining target oxygen saturation levels. ${ }^{38}$ Gradual weaning does seem preferable to abrupt weaning in terms of ROP risk, independent of the duration of oxygen therapy. ${ }^{39}$

\section{CONCLUSIONS}

Supplemental oxygen is a safe and effective treatment with a wide therapeutic index in the infant with established CLD who is not at risk of further progression of ROP. In such infants, oxygen saturations of $<92 \%$ should be avoided and a target range of at least $94-96 \%$ aimed for. Recent studies have shown the safety of higher oxygen saturation targets (95-99\%) in appropriate infants. Such a range will provide a buffer zone against desaturations during feeding and sleep. This target is consistent with current recommendations. ${ }^{40}$ Maintenance of oxygen saturations in this range reduces complications from pulmonary artery hypertension and promotes growth. The saturation target range for very preterm infants at risk of developing ROP is more controversial, but it seems clear that the therapeutic index is considerably narrower. Pulse oximetry monitoring can be an accurate and effective way to maintain oxygen saturations within target ranges, especially during sleep, when oxygen saturation is likely to fall to suboptimal levels.

\section{Authors' affiliations}

S Kotecha, Department of Child Health, University of Leicester, Leicester LE2 7LX, UK

J Allen, Division of Pulmonary Medicine and Cystic Fibrosis Center, The Children's Hospital of Philadelphia, University of Pennsylvania School of Medicine, Philadelphia, PA, USA

\section{REFERENCES}

1 Todd DA, Jana A, John E. Chronic oxygen dependency in infants born at 24-32 weeks' gestation the role of antenatal and neonatal factors. $J$ Paediatr Child Health 1997;33:402-7.

2 Palmisano JM, Martin JM, Krauzowicz BA, et al. Effects of supplemental oxygen administration in an infant with pulmonary artery hypertension. Heart Lung 1990;19:627-30.

3 Alpert BE, Gainey MA, Schidlow DV, et al. Effect of oxygen on right ventricular performance evaluated by radionuclide angiography in two young patients with chronic lung disease. Pediatr Pulmonol 1987; 3:149-52

4 Abman SH, Wolfe RR, Accurso FJ, et al. Pulmonary vascular response to oxygen in infants with severe bronchopulmonary dysplasia. Pediatrics $1985: 75: 80-4$

5 Goodman G, Perkin RM, Anas NG, et al. Pulmonary hypertension in infants with bronchopulmonary dysplasia. J Pediatr 1988;112:67-72.

6 Abman SH, Accurso FJ, Koops BL. Experience with home oxygen in the management of infants with bronchopulmonary dysplasia. Clin Pediatr 1984;23:471-6.

7 Groothuis JR, Rosenberg AA. Home oxygen promotes weight gain in infants with bronchopulmonary dysplasia. American Journal of Diseases of Children 1987;141:992-5.

8 Lifschitz MH, Seilheimer DK, Wilson GS, et al. Neurodevelopmental status of low birth weight infants with bronchopulmonary dysplasia requiring prolonged oxygen supplementation. J Perinatol 1987;7:127-32.

9 Doyle LW, Kitchen WH, Ford GW, et al. Outcome to 8 years of infants less than $1000 \mathrm{~g}$ birthweight: relationship with neonatal ventilator and oxygen therapy. J Paediatr Child Health 1991;27:184-8.

10 Terry TL. Extreme prematurity and fibroblastic overgrowth of persistent vascular sheath behind each crystalline lens. Am J Ophthalmol 1942;25:203-4.
11 Cross KW. Cost of preventing retrolental fibroplasia? Lancet 1973;ii:954-6.

12 Askie LM, Henderson-Smart DJ. Restricted versus liberal oxygen exposure for preventing morbidity and mortality in preterm or low birth weight infants. Cochrane Database Syst Rev 2000;CD00 1077.

13 Anonymous. Supplemental therapeutic oxygen for prethreshold retinopathy of prematurity (Stop-Rop), a randomized, controlled trial. I: primary outcomes. Pediatrics 2000;105:295-310.

14 Tin W, Milligan DWA, Pennefather P, et al. Pulse oximetry, severe retinopathy, and outcome at one year in babies of less than 28 weeks gestation. Arch Dis Child Fetal Neonatol Ed 2001;84:F106-10.

15 Hay W Jr, Bell EF. Oxygen therapy, oxygen toxicity, and the STOP-ROP trial. Pediatrics 2000;105:424-5.

16 Cunningham S, Fleck BW, Elton RA, et al. Transcutaneous oxygen levels in retinopathy of prematurity. Lancet 1995;346:1464-5.

17 Garg M, Kurzner SI, Bautista DB, et al. Clinically unsuspected hypoxia during sleep and feeding in infants with bronchopulmonary dysplasia. Pediatrics 1988;81:635-42

18 Singer L, Martin R, Hawkins SW, et al. Oxygen desaturation complicates feeding in infants with bronchopulmonary dysplasia after discharge. Pediatrics 1992;90:380-4.

19 Sekar KC, Duke JC. Sleep apnea and hypoxemia in recently weaned premature infants with and without bronchopulmonary dysplasia. Pediatr Pulmonol 1991;10:112-16.

20 Zanardo V, Trevisanuto D, Dani C, et al. Oxygen saturation in premature neonates with bronchopulmonary dysplasia in a hammock. Biol Neonate 1995;67:54-8.

21 Harris MA, Sullivan CE. Sleep pattern and supplementary oxygen requirements in infants with chronic neonatal lung disease. Lance 1995; $345: 831-2$

22 Fitzgerald D, Van Asperen $\mathrm{P}$, Leslie $\mathrm{G}$, et al. Higher $\mathrm{SaO}_{2}$ in chronic neonatal lung disease: does it improve sleep? Pediatr Pulmonol 1998;26:235-40

23 Durand $M$, Ramanathan R. Pulse oximetry for continuous oxygen monitoring in sick newborn infants. J Pediatr 1986;109:1052-6.

24 Hay WW Jr, Brockway JM, Eyzaguirre M. Neonatal pulse oximetry: accuracy and reliability. Pediatrics 1989;83:717-22

25 Ramanathan $\mathbf{R}$, Durand $M$, Larrazabal C. Pulse oximetry in very low birth weight infants with acute and chronic lung disease. Pediatrics 1987:79:612-17

26 Praud JP, Carofilis A, Bridey F, et al. Accuracy of two wavelength pulse oximetry in neonates and infants. Pediatr Pulmonol 1989;6:180-2.

27 Bhutani VK, Taube JC, Antunes N, et al. Adaptive control of inspired oxygen delivery to the neonate. Pediatr Pulmonol 1992;14:110-17.

28 Groeneveld $M$. Sending infants home on low-flow oxygen. J Obstet Gynecol Neonatal Nurs 1986;15:237-41.

29 Brown KA, Sauve RS. Evaluation of a caregiver education program: home oxygen therapy for infants. J Obstet Gynecol Neonatal Nurs 1994;23:429-35.

30 Beca JP, Torres J, Sfeir J, et al. Home oxygen therapy in children with bronchopulmonary dysplasia. Revista Chilena de Pediatria 1990;61:267-70

31 Sauve RS, McMillan DD, Mitchell I, et al. Home oxygen therapy. Outcome of infants discharged from NICU on continuous treatment. Clin Pediatr 1989:28:113-8.

32 Baraldi E, Carra S, Vencato F, et al. Home oxygen therapy in infants with bronchopulmonary dysplasia: a prospective study. Eur J Pediatr 1997; 156:878-82

33 Dunbar $\mathbf{H}$, Kotecha S. Domicilary oxygen for infants with chronic lung disease of prematurity. Care of the Critically III 2000;16:90-3.

34 Report of the Royal College of Physicians. Domiciliary oxygen therapy services. Clinical guidelines and advice for prescribers. London: Royal College of Physicians, 1999

35 Moyer-Mileur LJ, Nielson DW, Pfeffer KD, et al. Eliminating sleep-associated hypoxemia improves growth in infants with bronchopulmonary dysplasia. Pediatrics 1996;98:779-83.

36 Vermeulen MJ, Weening FT, Battistutta D, et al. Awake daytime oximetry measurements in the management of infants with chronic lung disease. J Paediatr Child Health 1999;35:553-7.

37 Simoes EA, Rosenberg AA, King SJ, et al. Room air challenge: prediction for successful weaning of oxygen-dependent infants. J Perinatol 1997; 17:125-9.

38 Askie LM, Henderson-Smart DJ. Early versus late discontinuation of oxygen in preterm or low birth weight infants. Cochrane Database Syst Rev 2000;CD001076.

39 Askie LM, Henderson-Smart DJ. Gradual versus abrupt discontinuation of oxygen in preterm or low birth weight infants. Cochrane Database Syst Rev 2000;CD001075

40 Poets $\mathbf{C}$. When do infants need additional inspired oxygen? A review of the current literature. Pediatr Pulmonol 1998;26:424-8. 


\section{LETTERS}

If you have a burning desire to respond to a paper published in $A D C$ or $F \& N$, why not make use of our "rapid response" option?

Log on to our website (www.archdischild. com), find the paper that interests you, click on "full text" and send your response by email by clicking on "submit a response".

Providing it isn't libellous or obscene, it will be posted within seven days. You can retrieve it by clicking on "read eletters" on our homepage.

The editors will decide, as before, whether to also publish it in a future paper issue.

\section{Aspiration pneumonia in association with oral vitamin $\mathrm{K}$}

Most infants born in the British Isles now receive vitamin $\mathrm{K}$ prophylaxis, and the trend towards oral administration continues. ${ }^{1}$ With the awareness that vitamin $\mathrm{K}$ is well absorbed from the gut ${ }^{2}$ and following publication of the report linking intramuscular vitamin $\mathrm{K}$ and childhood cancer, ${ }^{3}$ oral vitamin $\mathrm{K}$ prophylaxis has become more widespread. However, because of lack of uniform national policy, the practice of vitamin $\mathrm{K}$ administration varies from region to region. Cases of aspiration or anaphylaxis following oral vitamin $\mathrm{K}$ administration in neonates have not been previously reported.

We report three cases of aspiration associated with oral vitamin $\mathrm{K}$, Orakay, the preparation uniformly used in Northeast England Acute respiratory distress developed in previously well, breast fed neonates following administration of Orakay at home. All required hospital admission, and two of them had radiological evidence of aspiration.

Case 1: a 14 day old term boy was well until given a second dose of Orakay by his father. He immediately developed a cough, tachypnoea, and grunting, cried inconsolably, and refused feeds. On admission, he was apyrexial but had features of respiratory distress. A chest radiograph showed infiltration of the right perihilar and lower zones. A septic screen was normal. Two further doses of Orakay were given under hospital supervision without problems and he remained well.

Case 2: a 14 day old girl was well until the community midwife gave a second dose of Orakay. The baby coughed straight afterwards and remained very unsettled. Within an hour, she was grunting, tachypnoeic, and refusing feeds. On admission, she had features of respiratory distress. Oxygen saturation was $85 \%$ in air. A chest radiograph showed bilateral increased perihilar shadow. A septic screen was negative. She was discharged home on formula milk, and therefore did not need further Orakay.

Case 3: a 28 day old term girl was thriving and had tolerated two doses of Orakay well. When her father administered a third dose, she started to cough, became pale, unsettled, and tachypnoeic, and refused feeds. On examination, she had features of respiratory distress. A septic screen was negative. A chest radiograph was normal. After discharge, she was given a fourth dose of Orakay under hospital supervision and remained well.

Of note, even oral administration of vitamin $\mathrm{K}$ can occasionally be hazardous. This is of particular concern because Orakay is not licensed in the United Kingdom. There is an urgent need to develop a consensus policy and a product that is licensed, effective, easy to administer, and has minimal adverse effect.

V Bhandari, N On Tin, S R Ahmed Darlington Memorial Hospital, Darlington DL3 6HX UK; vidyabhandari@hotmail.com

\section{References}

1 Barton JS, Tripp JH, McNinch AW. Neonatal vitamin $\mathrm{K}$ prophylaxis in the British Isles: curren practice and trends. BM 1995;310:632-3.

2 McNinch AW, Upton C, Samuel M et al. Plasma concentration after oral or intramuscular vitamin $\mathrm{K}$ in neonates. Arch Dis Child 1985; 60:814-18

3 Golding J, Birmingham K, Greenwood R, et al. Intramuscular vitamin $\mathrm{K}$ and childhood cancer. BN 1992;305:341-6.

\section{Hypothesis waiting for proof: unwrapping neonates for transfer}

During transfer from the delivery suite to the neonatal intensive care unit (NICU), infants are traditionally wrapped in pre-warmed towels. Whether this is optimal remains unknown. We compared the effects on core temperature of wrapping or not wrapping neonates during their transfer from the delivery suite to the NICU.

After resuscitation, infants in both groups were transferred to a Vickers 77-transport incubator and left wrapped or unwrapped. Rectal temperature was recorded using a mercury thermometer before leaving the delivery suite and again, immediately after transfer into a NICU incubator. The study was granted ethical approval.

Our findings are summarised in the table. There were no significant demographic differences between the two groups. While the mean transfer time was longer in the unwrapped group, the mean temperature change during transit was lower although neither difference reached statistical significance. No hypothermia (rectal temperature $<36^{\circ} \mathrm{C}$ ) occurred in either group.
Wrapping infants in towels prevents convective heat gain. Additionally, leaving infants unwrapped allows essential clinical observation.

Despite the limitations of this small study our findings challenge the practice of wrapping infants and warrant further examination in larger clinical studies.

D J Hawkes, D G Spendley, M Alfaham Departments of Child Health and Medical Physics, Cardiff and Vale NHS Trust, Llandough Hospital, Cardiff CF64 2XX, UK

Correspondence to: Dr Alfaham

Mazin.Alfaham@CardiffandVale.wales.nhs.uk

\section{Diuretics in CLD}

This symposium on chronic lung disease of prematurity (CLD) by Kotecha et al ${ }^{1}$ covered important aspects and controversies in the management of CLD. We accept the authors inability to cover all aspects of management We feel that some space could have been devoted to diuretics in management of CLD. Nearly all patients with CLD of some stage of their disease will receive diuretics and most of them will be on them for a long time. We came across only one systemic review by Brion et $\mathrm{al}^{2}$ in the Cochrane database. Conclusion of the authors was that there was no beneficial effect of using distal tubular diuretics for more than 4 weeks after initial stage. There was also no benefit in adding potassium sparing diuretics or newer diuretics like metalozone. Inspite of very little evidence base for diuretics in CLD, one finds nearly all CLD patients on a diuretic cocktail. In addition to their effect on electrolytes, they affect $\mathrm{Ca} / \mathrm{PO}$ metabolism. This may exacrebate osteopenia of prematurity and may have adverse effect on lung compliance. There is a need for more discussion or clear guidelines on this issue.

V A Pai Southmead Hospital, Bristol, UK

B Pai

Royal United Hospital, Bath, UK

Correspondence to: Flat 3, 19 Newbridge Road, Bath BAl 3HE binapai@hotmail.com

\section{References}

1 Kotecha S. Management issues in CLD of prematurity. Arch Dis Child Fetal Neonatal Ed 2002;87:F2.

2 Brion LP, Primhak RA. Cochrane Database Systemic Review, 2002;1:CD001453.
Table 1 Demographics of the two study groups and temperature difference

\begin{tabular}{lll}
\hline & Wrapped & Unwrapped \\
\hline Number & 10 & 10 \\
Male:female & $5: 5$ & $3: 7$ \\
Mean weight & $1.635(\mathrm{~kg})$ & $1.595(\mathrm{~kg})$ \\
Weight range & $1.29-2.35(\mathrm{~kg})$ & $1.08-2.24(\mathrm{~kg})$ \\
Mean gestation & $32 / 40$ & $32 / 40$ \\
Gestation range & $30 / 40-34 / 40$ & $27 / 40-33 / 40$ \\
Transit time & $5 \mathrm{~min} 48 \mathrm{sec}$ & $7 \mathrm{~min} 6 \mathrm{sec}$ \\
Range & $4-10 \mathrm{~min}$ & $5-10 \mathrm{~min}$ \\
Temperature difference & $-0.34\left({ }^{\circ} \mathrm{C}\right)$ & $-0.21\left({ }^{\circ} \mathrm{C}\right)$ \\
Range & -0.7 to $+0.1\left({ }^{\circ} \mathrm{C}\right)$ & -0.5 to $+0.1\left({ }^{\circ} \mathrm{C}\right)$ \\
\hline
\end{tabular}




\section{Positioning long lines: response to Reece et al}

Percutaneously inserted central venous lines are widely used in neonatal intensive care to administer parenteral nutrition and medications. ${ }^{1}$ It is important to ascertain the position of the line tip before use as incorrectly positioned long lines can lead to life threatening complications like cardiac tamponade and pulmonary oedema. ${ }^{2}{ }^{3}$

Reece et al suggested that it is prudent to use a routine contrast radiograph to localise the line tip in newborn infants. ${ }^{4}$ We would like to comment on their suggestion and report a relevan study we carried out on our neonatal unit.

Intravenous water soluble contrast is not commonly used in neonates and very little is known about its potential side effects in premature infants. ${ }^{5}$ Studies have shown that renal clearance is prolonged in premature infants because of renal immaturity. ${ }^{6}$ Data in children have shown a number of possible side effects, including hypotension and cardiac arrhythmia. ${ }^{5}$ Moreover, obtaining an intravenous contrast radiograph of a long line would require additional medical and nursing time as a doctor would have to "gown up" for the procedure. This may not be logistically feasible in some busy neonatal units, especially out of hours.

Reece et al were unable see the line tip clearly in two cases, even after a contrast study. ${ }^{4}$ This was due to delay between the injection of contrast and the radiographer exposing the film. This shows that fine coordination is required between the radiographer and the person injecting the contrast. Specific training may necessary.

We performed a retrospective study of the reliability of plain radiographs in identifying the site of the long line tip in our tertiary neonatal intensive care unit. Over a 10 month period all 27 babies who had long lines inserted were included. In all cases an Epicutaneo-Cava-Katheter (Vygon, UK) was inserted. This is the same catheter as that used by Reece and colleagues. ${ }^{4}$ Our placement aim was also similar to that in their study. ${ }^{4}$

The position of the line tip on the postinsertion $x$ ray was independently reviewed by an experienced junior doctor (IB) and a consultan neonatal radiologist (SB). There was agreement between the two investigators in 25/27 (92.6\%) cases. No complications due to line placements were observed during the study period.

We therefore feel that a plain radiograph is the safest, quickest, and cheapest way to ensure the safety of the line.

I Bagchi, J A Nycyk, S Bodicoat Neonatal Intensive Care Unit, City Hospital, Birmingham, UK; bagchi@btinternet.com

\section{References}

1 Brain AJ, Roberton NRC, Rennie JM. Textbook of neonatology. London: Churchill Livingston, 1999:1376.

2 Goutail-Flaud MF, Sfez M, Berg A, et al. Central venous catheter related complications in newborns and infants: a 587-case survey. $J$ Pediatr Surg 1991;26:645-50.

3 Pesce C, Mercurella A, Musi L, et al. Fatal cardiac tamponade as a late complication of central venous catheterization: a case report. Eur J Pediatr Surg 1999;9:113-15.

4 Reece A, Ubhi T, Craig AR, et al. Positioning long lines: contrast versus plain radiography. Arch Dis Child Fetal Neonatal Ed 2001;84:F129-F30.

5 Chapman S, Nakielny R. A guide to radiological procedures, 3rd edn. London: Bailliere Tindal, 1993:24-5.

6 Johnson WH Jr, Lloyd TR, Victorica BE, et al. lodixanol pharmacokinetics in children. Pediatr Cardiol 2001;22:223-7.

\section{Neonatal sepsis in Peshawar}

We wish to raise a few concerns regarding the study reported by Rahman and colleagues.

We found it surprising that only five species of microorganisms were isolated in this series of over 1000 blood cultures obtained from neonates with sepsis. Similar studies done in other major cities of Pakistan, with much smaller sample sizes, have shown a wider spectrum of pathogens. Anwer $e t a^{2}$ showed 11 species types in 109 blood cultures, Bhutta and Yusuf ${ }^{3}$ showed 13 species types in 38 cultures, Khan and $\mathrm{Akram}^{4}$ showed more than eight different species types from 89 cultures, and Bhutta reported 11 species types in a series of 276 positive blood cultures. In addition to the five species causing neonatal sepsis reported by Rahman et al (Esherichia coli 36.6\%, Staphylococcus aureus $29.5 \%$, Pseudomonas $22.4 \%$, Klebsiella $7.6 \%$, and Proteus $3.8 \%$ ), all the other investigators have also reported Serratia spp and Enterococcus, and most reported Streptococcus pneumoniae, Salmonella spp, and group B Streptococcus. Although the authors do not clearly state whether they excluded hospital acquired infections in their series, the studies reported by Bhutta ${ }^{5}$ did exclude nosocomial infections.

The antimicrobial susceptibility data reported by Rahman et al are not interpretable as the number of microorganisms on which antimicrobial susceptibility testing was performed is not presented. In addition, the susceptibility results are not internally consistent; $60 \%$ of the Staphylococcus aureus tested are reported to be ampicillin sensitive but only 27\% were Amoxicillin + Clavulanate (Augmentin) sensitive. This represents a highly unusual susceptibility result with a high percentage of $S$ aureus not producing betalactamase enzymes to inactivate penicillin (ampicillin), but still showing resistance to a penicillin-beta-lactamase-inhibitor combination such as Augmentin. We wonder if the $60 \%$ reported sensitivity of $S$ aureus to ampicillin is erroneous since the vast majority of $S$ aureus, even in developing countries, are now penicillin (ampicillin) resistant. ${ }^{5-8}$ We also find the $73 \%$ resistance rate of $S$ aureus to amoxicillin-clavulanate (which is equivalent to methicillin resistance for $S$ aureus) surprisingly high, and question if this indicates the presence of hospital acquired infections in this series.

S A Ali, T A Khan, A K M Zaidi Department of Paediatrics, The Aga Khan University, Karachi, Pakistan

Correspondence to Dr Ali; syed.ali@aku.edu

\section{References}

1 S Rahman, A Hameed, M T Roghani, et al. Multidrug resistant neonatal sepsis in Peshawar, Pakistan. Arch Dis Child Fetal Neonatal Ed 2002;87:F52-F54.

2 Anwer SK, Mustafa S, Pariyani S, et al. Neonatal sepsis: an etiological study. J Pak Med Assoc 2000;50:91-3.

3 Bhutta ZA, Yusuf K. Early onset neonatal sepsis in Pakistan: a case control study of risk factors in a birth cohort. Am J Perinatol 1997; 14:577-81.

4 Khan IA, Akram DS. Neonatal sepsis-etiological study. J Pak Med Assoc 1987:37:327-30

5 Bhutta ZA. Spectrum of nonnosocomial neonatal sepsis. State of the World's newborns: Pakistan. Saving Newborn Lives Oct 2001

6 Kuruvilla KA, Pillai $S$, Jesudason $M$, et al. Bacterial profile of sepsis in a neonatal unit in South India. Indian Pediatr 1998;35:851-8.
7 Tallur SS, Kasturi AV, Nadgir SD, et al. Clinico-bacteriological study of neonatal septicemia in Hubli. Indian J Pediatr 2000;67: 169-74.

8 Ako-Nai AK, Adejuyigbe EA, Ajayi FM, et al. The bacteriology of neonatal septicemia in lle-lfe, Nigeria. J Trop Pediatr 1999;45:146-51.

\section{Effect of head up tilting on oxygenation}

We read with interest the paper by Dimitriou et $a l^{1}$ in which it was confirmed again that head up tilting to 45 degrees results in better oxygenation in stable preterm neonates. However compared with our study, ${ }^{2}$ in which the same effect was observed, there is a (probably) significant difference. Their infants were studied in the horizontal prone, in the horizontal supine and in the $45^{\circ}$ head up tilt supine position whereas in our study all infants were studied in the prone position including the $45^{\circ}$ head up tilt. We had then hypothesised that the combination of the prone position and the $45^{\circ}$ head up tilt could facilitate diaphragmatic activity.

I do not think that this hypothesis can be totally dismissed by the results of Dimitriou et $a l^{1}$ as suggested by the authors, since their infants were studied in different positionsthat is, supine in their study and prone in our study.

\section{HD Dellagrammaticas} hdellagr@ath.forthnet.gr

\section{References}

1 Dimitriou G, Greenough A, Pink L, et al. Effect of posture on oxygenation and respiratory muscle activity in convalescen infants. Arch Dis Child Fetal Neonatal Ed 2002:86:F147-50.

2 Dellagrammaticas HD, Kapetanakis J, Papadimitriou $M$, et al. Effect of body tilting on physiological functions in stable very low birthweight neonates. Arch Dis Child $1991 ; 66: 429-32$

\section{Authors' reply}

We thank Professor Dellagrammaticas for his comments on our study. ${ }^{1}$ Dellagrammaticas et $a l^{2}$ hypothesised that the combination of the prone posture and the 45 degree head up tilt position could facilitate diaphragmatic activity. We however, propose that the improvement in oxygenation seen in the head up tilt position ${ }^{1}$ was more likely to be due to a change in lung volume. In the head up tilt position, the weight of the abdominal contents on the diaphragm is reduced, tending to increase functional residual capacity. ${ }^{3}$ In contrast, ultrasonographic examination ${ }^{4}$ has demonstrated that the diaphragm was significantly thicker at end expiratory volume in the prone rather than the supine position, which is likely to result in reduced diaphragm strength. Indeed, we demonstrated ${ }^{1}$ Pimax (a measure of respiratory muscle strength) was lower in the prone compared to the supine position and the supine posture with $45^{\circ}$ head tilt.

A Greenough, G Dimitrou

Children Nationwide Regional Neonatal Intensive

Care Unit, King's College Hospital, London, UK

Correspondence to Professor Greenough, Department of Child Health, King's College Hospital, London SE5 9RS, UK; anne.greenough@kcl.ac.uk 


\section{References}

1 Dimitriou G, Greenough A, Pink L, et al. Effect of posture on oxygenation and respiratory muscle strength in convalescent neonates. Arch Dis Child Fetal Neonatal Ed 2002;86:F147F50.

2 Dellagrammaticas HD, Kapetankis J, Papadimitriou $M$, et al. Effect of body tilting on physiological functions in stable very low birth weight neonates. Arch Dis Child 1991:66:429-32

3 Thoresen M, Cowan F, Whitelaw. Effect of tilting on oxygenation in newborn infants. Arch Dis Child 1988;63:315-17.

4 Rehan VK, Nakashima JM, Gutman A, et al. Effects of supine and prone position on diaphragmatic thickness in healthy term infants. Arch Dis Child 2000;83:234-8.

\section{Effect of salt supplementation of newborn premature infants on neurodevelopmental outcome at 10-13 years of age}

I read with interest the report by Al-Dahhan and colleagues ${ }^{1}$ on the beneficial effect of $\mathrm{NaCl}$ supplementation of preterm infants during the neonatal period on their later neurodevelopmental outcome. They found better memory, learning, language, and educationa performances at the age of 10-13 years in prematures who were given $4-5 \mathrm{mmol} /$ day $\mathrm{NaCl}$ when compared with those not receiving $\mathrm{NaCl}$ supplement. In this regard it is relevant to mention our most recent findings describing a new aspect of the relation of neonatal sodium homoeostasis to central nervous system function. Namely, we showed that hyponatraemia is one of the most significant risk factors for development of sensorineural hearing impairment detected by transient evoked otoacoustic emission and confirmed by auditory brainstem response. $^{2}$

In addition, I consider their report raises an important ethical issue, in that I regard their selection of references as subjective and arbitrary. In particular, the work of our group in revealing some major features of sodium homoeostasis in premature infants has been ignored; for example, renal salt wasting, sodium depletion, and hyponatraemia, ${ }^{3-5}$ and the first introduction of $\mathrm{NaCl}$ supplementation in a dose of $3-5 \mathrm{mmol} / \mathrm{kg} /$ day to prevent sodium deprivation, to improve somatic stability, and to avoid untoward clinical consequences. $^{6}$

E Sulyok

Professor and Chairman, County Children's Hospital, Institute of Health Promotion and Family Care, Faculty of Health Sciences, University of Pecs, H-7624 Pecs, PO Box 76, Hungary

\section{References}

1 Al-Dahhan, Jannoun L, Haycock GB. Effect of salt supplementation of newborn premature infants on neurodevelopmental outcome at 10-13 years of age. Arch Dis Child Fetal Neonatal Ed 2002;86:F120-3.

2 Ertl T, Hadzsiev K, Vincze O, et al. Hyponatraemia and sensorineural hearing loss in preterm infants. Biol Neonate 2001;79:109-12.

3 Sulyok E. The relationship between electrolyte and acid-base balance in the premature infant during early postnatal life. Biol Neonate 1971;17:227-37.

4 Sulyok E, Heim T, Soltész G, et al. The influence of maturity on renal control of acidosis in newborn infants. Biol Neonate 1972;21:418-35.

5 Sulyok E. Sodium homeostasis in preterm infants [letter]. Lancet 1975;i:930.

6 Sulyok E, Németh $M$, Tényi I, et al. Relationship between the postnatal development of the renin-angiotensin-aldosterone system and electrolyte and acid-base status of the $\mathrm{NaCl}$ supplemented premature infants. In: Spitzer A, ed. The kidney during developmen morphology and function. New York: Masson Publishing, 1982:273-81.

\section{Author's reply}

Methinks Professor Sulyok doth protest too much. His early, pioneering work on electrolyte balance in the newborn is well known, and extensively cited in an earlier review of the subject co-authored by myself. ${ }^{1}$ In this, inter alia, his study of the effect of salt supplementation on the renin-angiotensinaldosterone system ${ }^{2}$ is quoted in support of the hypothesis that hyponatraemia in premature infants is due to salt depletion rather than water retention. The reason these papers were not cited in the present paper is that they are not relevant to it. The paper is not a historical or general review of hyponatraemia in the newborn but the results of a study specifically designed to examine neurodevelopmental outcome in two particular groups of infants previously studied by ourselves..$^{3-5} \mathrm{His}$ recent study of hyponatraemia and sensorineural deafness in preterm infants ${ }^{6}$ had not been published when our paper was submitted to the Archives, although we would certainly have referred to it if it had been.

G Haycock Blackheath, London SE3 9DE, UK; GHayc37893@aol.com

\section{References}

1 Haycock GB, Aperia A. Salt and the newborn kidney. Pediatr Nephrol 1991;5:65-70.

2 Sulyok E, Németh $M$, Tényi I, et al. Relationship between the postnatal development of the renin-angiotensin-aldosterone system and the electrolyte and acid-base status in the sodium chloride supplemented premature infant. Acta chloride supplemented premature infant. Act

3 Al-Dahhan J, Haycock GB, Chantler C, et al. Sodium homeostasis in term and preterm neonates. I. Renal aspects. Arch Dis Child 1983:58:335-42.

4 Al-Dahhan J, Haycock GB, Chantler C, et al. Sodium homeostasis in term and preterm neonates. II. Gastrointestinal aspects. Arch Dis Child 1983:58:343-5.

5 Al-Dahhan J, Haycock GB, Nichol B, et al. Sodium homeostasis in term and preterm neonates. III. The effect of salt supplementation. Arch Dis Child 1984;59:945-50.

6 Ertl T, Hadzsiev K, Vincze O, et al. Hyponatremia and sensorineural hearing loss in preterm infants. Biol Neonate

2001;79:109-12.

\section{CORRECTION}

We would like to apologise for an error that occured in the paper Oxygen therapy for infants with chronic lung disease by $\mathrm{S}$ Kotecha and $\mathrm{J}$ Allen (Arch Dis Child Fetal Neonatal Ed 2002;87:F11-F14). The following sentence, under the heading Weaning from home oxygen, should have read: Vermeulen et al showed that infants who could be weaned from oxygen had awake median saturations of $97 \%$ during one hour awake studies, spent only $14 \%$ of time with saturation $\leqslant 95 \%$ and $2 \%$ of time $\leqslant 92 \%$. 